\title{
Impedance-based cell monitoring: barrier properties and beyond
}

\author{
Kathrin Benson, Sandra Cramer and Hans-Joachim Galla*
}

\begin{abstract}
In multicellular organisms epithelial and endothelial cells form selective permeable interfaces between tissue compartments of different chemical compositions. Tight junctions which connect adjacent cells, control the passage of molecules across the barrier and, in addition, facilitate active transport processes. The cellular barriers are not static but can be deliberately modulated by exposure to specific external stimuli. In vitro models representing the essential absorption barriers of the body are nowadays available, thus allowing investigation of the parameters that control permeability as well as transport processes across those barriers. Independent of the origin of the barrier forming cells, techniques are needed to quantify their barrier integrity. One simple assay is to measure the permeability for given hydrophilic substrates possessing different molecular weights like sucrose or dextrans. However, this technique is time-consuming and labor-intensive. Moreover, radioactive or fluorescently-labeled substrates are needed to allow easy analytical detection. Finally, if transport processes are investigated, the standard permeant may interfere with the transport process under investigation or might even alter the barrier integrity by itself. Thus, independent, non-invasive techniques are needed to quantify the barrier integrity continuously during the experiment. Such techniques are available and are mainly based on the measurement of the transendothelial or transepithelial electrical resistance (TEER) of barrier forming cells grown on porous membranes. Simple devices using two sets of electrodes (so-called Voltohmeters) are widely used. In addition, an easy-to-use physical technique called impedance spectroscopy allows the continuous analysis of both the TEER and the electrical capacitance giving additional information about the barrier properties of cells grown on permeable membranes. This technique is useful as a quality control for barrier forming cells. Another impedance-based approach requires cells to be grown directly on solid, micro-structured electrodes. Here, we will discuss the physical background of the different techniques; advantages, disadvantages, and applications will be scrutinized. The aim is to give the reader a comprehensive understanding concerning the range and limits of the application, mainly focusing on endothelial cells.
\end{abstract}

Keywords: Barrier forming cells, Endothelium, Epithelium, Blood-brain barrier, Electrical resistance, TEER, Impedance spectroscopy

\section{Review}

\section{Barrier-forming cells}

A characteristic feature of epithelial as well as endothelial cell layers is the formation of intercellular junctions resulting in a tight cellular barrier separating the apical (luminal) from the basolateral (abluminal) side. These cell layers form selectively permeable interfaces between compartments of different chemical composition, thus controlling diffusion along the paracellular

\footnotetext{
* Correspondence: Gallah@uni-muenster.de

Institut für Biochemie, Westfälische Wilhelms-Universität Münster, Wilhelm Klemm Straße 2, Münster 48149, Germany
}

way as well as transport processes through intracellular pathways. This is guaranteed by the so-called tight junctions (intercellular connections) that seal the intercellular cleft [1]. An intact barrier is crucial for the physiological activities of the corresponding tissue. However, the barrier is not static but can be modulated by specific stimuli to open and close selectively, thus allowing controlled passage from the blood to the brain or vice versa [2-4]. Developing methods to overcome the barrier is an important issue and highly relevant for medical treatment of diseases within the barriers. Drug delivery systems or strategies to open the barrier
C Biomed Central

(C) 2013 Benson et al.; licensee BioMed Central Ltd. This is an Open Access article distributed under the terms of the Creative Commons Attribution License (http://creativecommons.org/licenses/by/2.0), which permits unrestricted use, distribution, and reproduction in any medium, provided the original work is properly cited. 
temporarily will help to allow medication to cross the blood-brain and the blood-CSF (cerebrospinal fluid) barrier as well as other barriers such as in the intestine, the kidney, the testis and the placenta. Adequate in vitro models are nowadays available, based on cell cultures grown on permeable supports [5]. These are of major importance since the setup offers full access to both the apical and the basolateral compartments. In vitro models can, in principle, be based on primary cells $[6,7]$ or cell lines $[8,9]$. However, in case of bloodbrain barrier (BBB) models most cell lines do not express barrier properties similar to in vivo conditions [10]. Thus care has to be taken if such cells are used for transport experiments.

Since the presence of an intact barrier is crucial for reliable in vitro experiments, techniques had to be developed to quantify the barrier integrity. One possibility is to measure the permeability for small hydrophilic substances like radioactively labeled sucrose or low molecular weight fluorescent dyes [11]. A straightforward method is the measurement of the TEER. A scrutiny of different TEER measurements will be given here. The major focus will be on techniques that allow automated long-term monitoring of barrier-relevant parameters including the dynamic processes within the tight junction network.

\section{TEER measurement according to Ohm's law}

A quantitative measure describing the barrier integrity is the electrical, ohmic resistance of the cell layer. In principle it can be determined by a simple, direct current (DC) based approach: a defined DC voltage, U, is applied to two electrodes, one on each side of the cell layer. The resulting current, I, is measured leading to the ohmic resistance $\mathrm{R}$ according to Ohm `s law ( $\mathrm{R}=\mathrm{U} /$ I). However the DC current can easily cause adverse effects on both the cells and the electrodes. The latter point has been avoided in case of the widely-used, socalled Epithelial Voltohmmeter (EVOM) [12]. Here an alternating current $(\mathrm{AC})$ square wave with a frequency of $12.5 \mathrm{~Hz}$ is used to avoid charging of the cell layer and the electrodes (Figure 1). However, as a handheld device with a chopstick-like arrangement of the electrodes, the resulting TEER readings depend strongly on the position of the probing electrodes. The required movement of the electrodes from one well to the other easily causes disturbances and is attended by a disruption of the physiological conditions as the cell cultures have to be temporarily removed from the incubator. Furthermore, the inherent inhomogeneity of the electric field across the cell layer typically leads to a systematic overestimation of TEER [13]. Altogether, there is a significant risk of obtaining erroneous results with this technical approach.

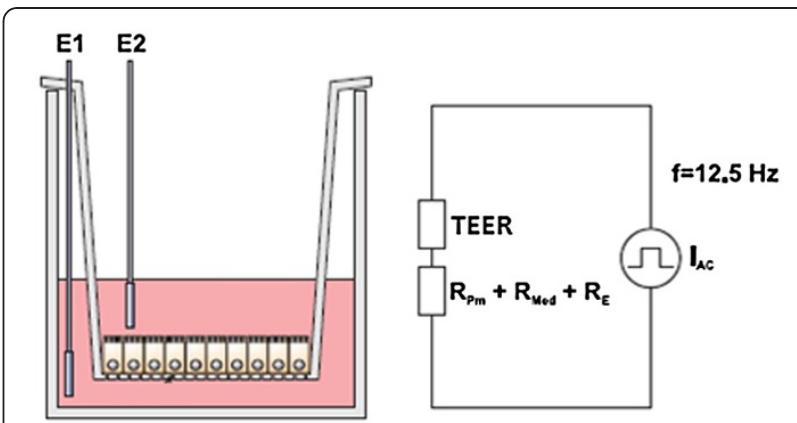

Figure 1 Impedance measurements with chopstick-like electrodes. The chopstick-like electrodes (E1,E2) are traditionally used to determine the electric resistance of cells grown on filter inserts. The ohmic resistance of the cell layer (TEER), the cell culture medium in the upper and lower compartment $\left(R_{\text {Med }}\right)$, the membrane of the filter inserts $\left(R_{p m}\right)$ and electrode-medium interface $\left(R_{E}\right)$ all contribute to the total electric resistance. $I_{A C}$ : alternating current. Adapted from [14] with permission.

\section{Automated impedance-based cell monitoring under physiological conditions using the cellZscope ${ }^{\circledR}$ device Basics of the technique}

Impedance spectroscopy is a highly reliable technique to measure the transendothelial or transepithelial electrical resistance (TEER). In impedance spectroscopy the frequency of an applied AC voltage is swept while measuring the amplitude and the phase of the resulting $\mathrm{AC}$ current. The resulting total impedance, Z, contains information not only about the TEER, but also the capacitance of the cell layer can be extracted and provided as a readout parameter. This non-invasive method can be applied to living cells without markers and allows them to be monitored during growth and differentiation [14]. Additionally, the barrier properties can be characterized before

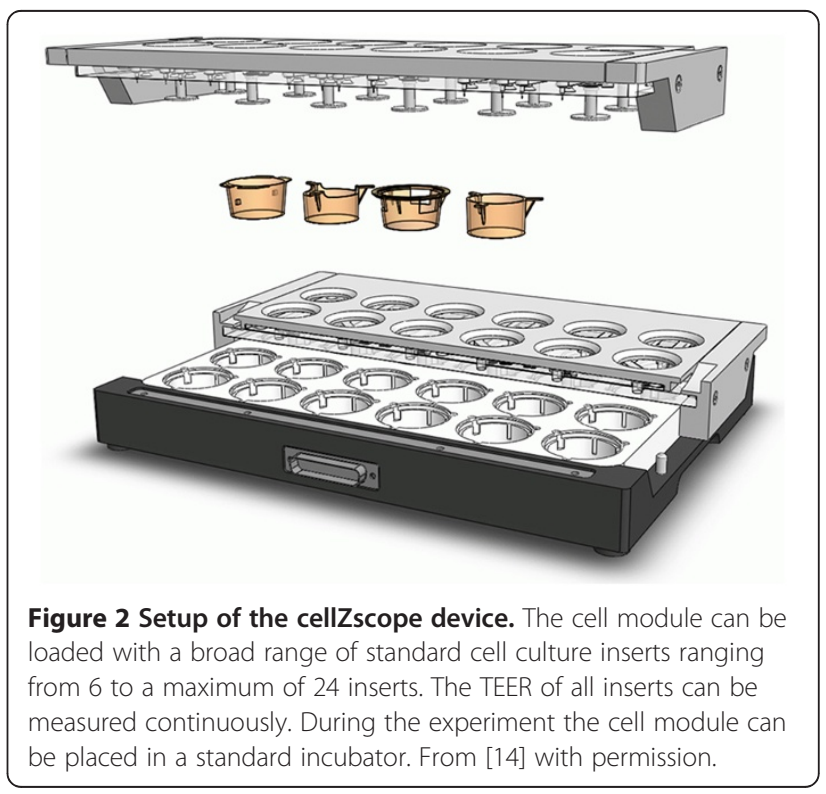




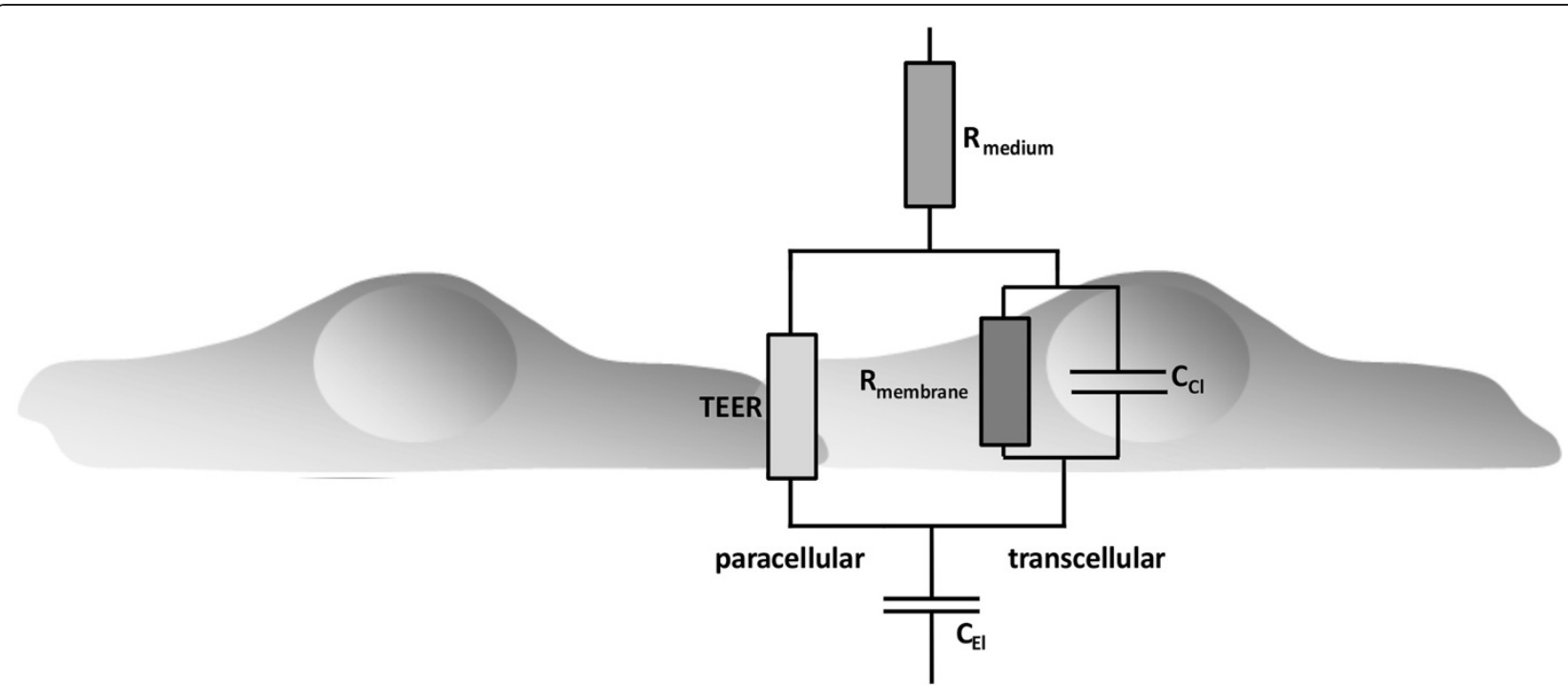

Figure 3 Equivalent circuit diagram describing the contribution of the trans- and paracellular pathway to the total impedance, $Z$, of the cellular system. TEER, transendothelial electric resistance; $C_{E l}$, capacitance of the electrodes; $C_{C l}$, capacitance of the cell layer; $R_{\text {medium, }}$ ohmic resistance of the medium; $R_{\text {membrane, }}$ ohmic resistance of the membranes. Please note that for most epithelial cells the TEER can be dominated by the transcellular pathway. This is true for tight epithelia already under resting conditions and, in leaky epithelia, after activation of ion channels.

using the cultures in subsequent experiments. To examine the TEER of cells grown on the porous membrane of standard cell culture inserts, a computer-controlled multiwell device that automatically derives all important parameters has been developed (cellZscope, nanoAnalytics $\mathrm{GmbH}$, Muenster, Germany, Figure 2).

In order to apply impedance spectroscopy to cellular systems and to retrieve the parameters needed to characterize barrier properties, an equivalent electrical circuit diagram and corresponding mathematical models have to be applied. A circuit diagram suitable to derive the total impedance $\mathrm{Z}$ of the cellular system is shown in Figure 3. Here, the current can either take the paracellular pathway through the intercellular cleft or the transcellular pathway across the cells. Within the paracellular pathway the tight junctional proteins represent an ohmic resistance (TEER) in the circuit diagram while each lipid bilayer in the transcellular pathway, can be described as a parallel circuit of an ohmic resistance $\left(R_{\text {membrane }}\right)$ and an electric capacitance, $\mathrm{C}_{\mathrm{cl}}$. Within the considered frequency range, the high resistance of the membrane causes the current to flow predominantly across the capacitor and allows us, in first-order
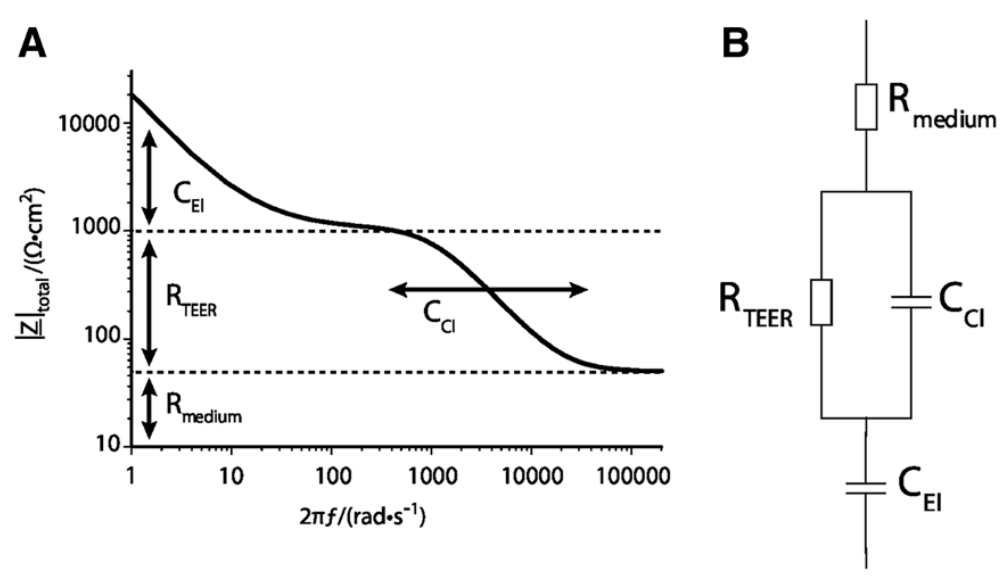

Figure 4 (A) Schematic impedance spectrum of a cell monolayer at different frequencies. (B) Equivalent electrical circuit diagram for a cell monolayer. At mid-range frequencies the cell-related parameters TEER and capacitance $C_{c l}$ are contributing predominantly to the total impedance. At the lower end of the frequency range the spectrum is dominated by the capacity of the electrodes $\left(C_{E I}\right)$. At high frequencies the capacitors $C_{c l}$ and $C_{e l}$ become increasingly conductive and the remaining total impedance converges to the resistance of the medium ( $R_{\text {Medium }}$ ). Adapted from [15] with permission. 


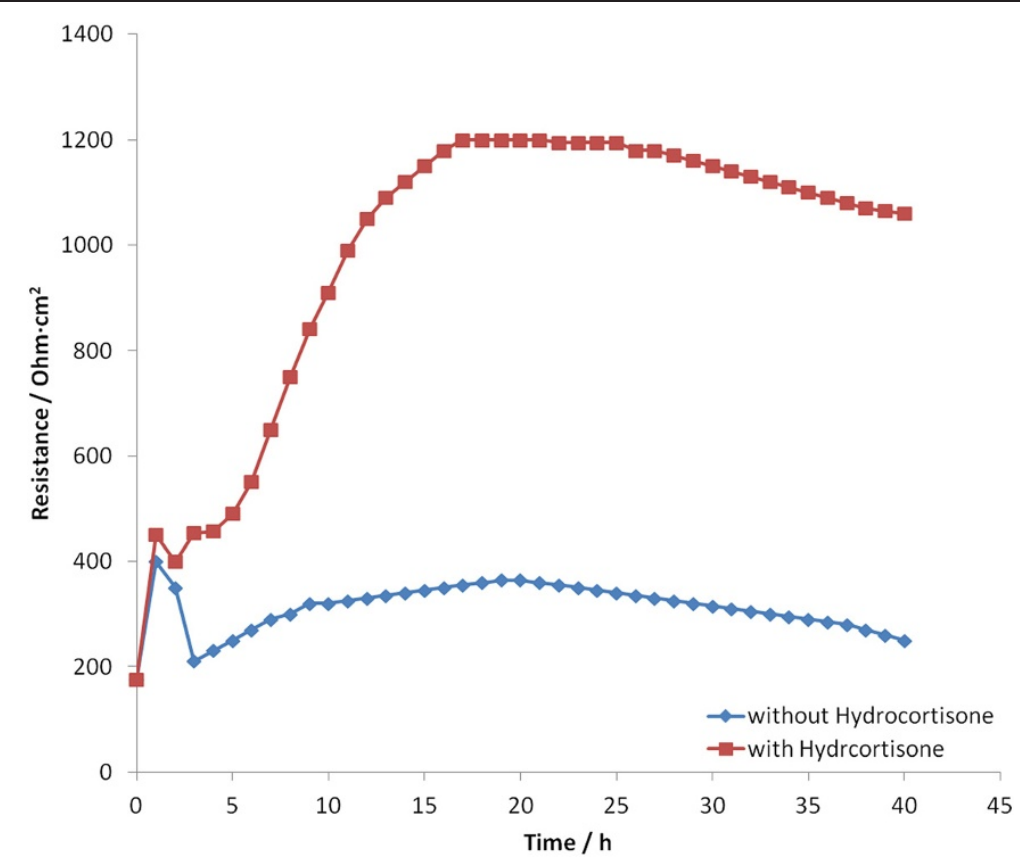

Figure 5 Development over time of the TEER of primary porcine capillary endothelial cells cultured in serum-free medium supplemented with hydrocortisone (orange curve) and without hydrocortisone (blue curve): In the presence of hydrocortisone an increase of the TEER is observed due to improved barrier integrity. Adapted from [18] with permission.

approximation, to ignore the membrane resistance and to summarize the apical and basolateral membranes in one capacitance $\left(\mathrm{C}_{\mathrm{cl}}\right)$. In addition, both the resistance of the surrounding medium $\left(\mathrm{R}_{\text {medium }}\right)$ and the capacitance of the electrodes $\left(C_{\mathrm{el}}\right)$ need to be considered as well. Taking all components together; a simplified electrical circuit diagram can be established and a non-linear frequency dependency of the total impedance, $\mathrm{Z}$, is found. On the basis of the described parameters an algorithm can be used to fit the experimental data (Figure 4, [15]). At mid-range frequencies the cell-related parameters TEER and capacitance $\mathrm{C}_{\mathrm{cl}}$ are predominantly contributing to the total impedance. At the lower end of the frequency range the spectrum is dominated by the capacity of the electrodes. At high
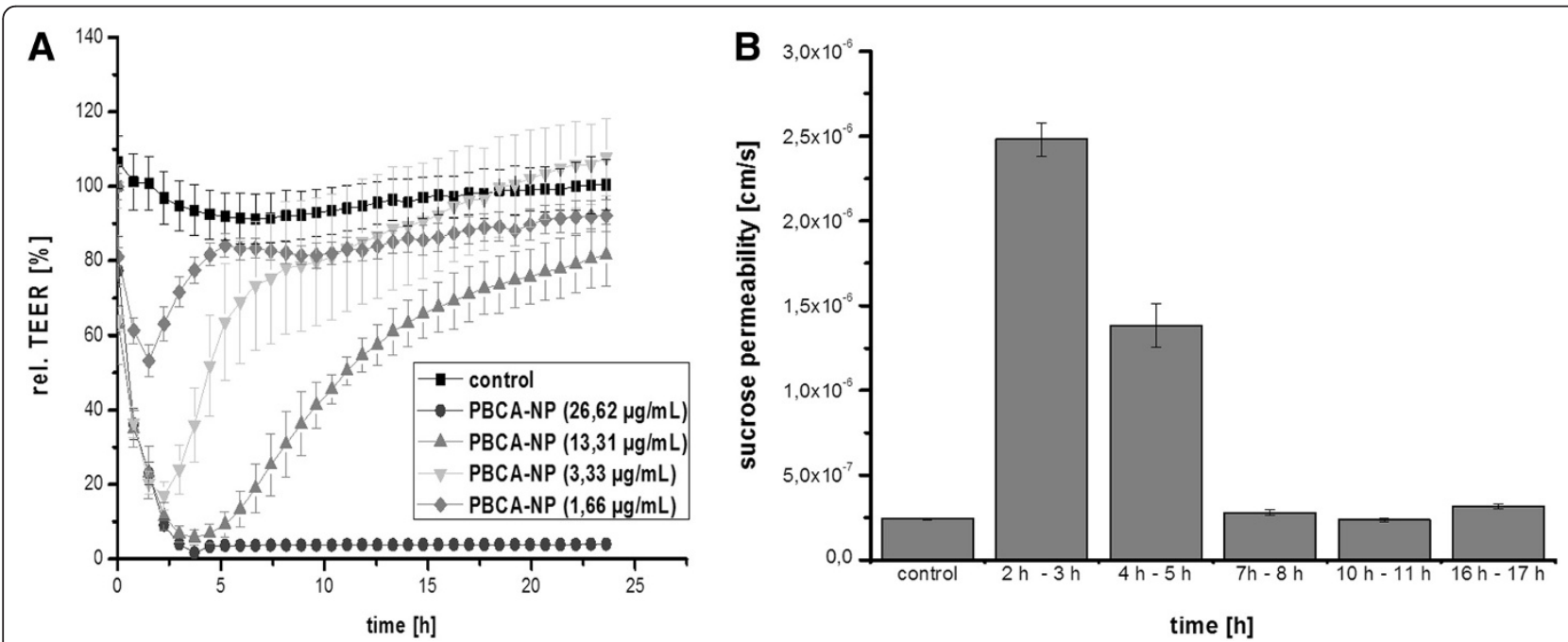

Figure 6 Influence of poly(butyl)cyanoacrylate nanoparticles (PBCA-NP) on the integrity of porcine brain capillary endothelial cells (PBCEC). (A) TEER development over time after the addition of PBCA-NP in different concentrations. (B) ${ }^{14} \mathrm{C}-$ Sucrose permeability at different times after the addition of PBCA-NP $(13.31 \mu \mathrm{g} / \mathrm{mL})$. From [20] with permission. 
frequencies the capacitors $\mathrm{C}_{\mathrm{cl}}$ and $\mathrm{C}_{\mathrm{el}}$ become increasingly conductive and the remaining total impedance converges to $\mathrm{R}_{\text {Medium }}$ (Figure 4 ).

Based on the equivalent circuit, the corresponding modeling computer software can be employed to determine automatically best fit parameters and to extract the TEER and the capacitance $\mathrm{C}_{\mathrm{cl}}$ as readout parameters. Further possible contributions to the cell layer's total impedance (for example the cell membrane resistance change) can be neglected in this first order approximation. For a deeper understanding of the mathematical difference between resistance and impedance, imaginary numbers and vectors have to be considered [16].

\section{Applications of impedance measurements using filter systems}

The effect of glucocorticoids on the properties of the bloodbrain barrier

The barrier-strengthening effect of hydrocortisone has been proven by electrical measurements. Hoheisel et al. [17] were able to show an increase in TEER of porcine cells after addition of hydrocortisone (Figure 5) [18]. Also, Weidenfeller et al. were able to observe this barrier strengthening effect in murine cells after application of different glucocorticoids [19]. Using impedance measurements it was also found that the effect of glucocorticoids can be completely inhibited by the glucocorticoid-receptor antagonist mifepristone. Interestingly, the described effect can be achieved by a different range of glucocorticoids but not by mineralocorticoids.

\section{Impedance measurement as quality control}

Techniques that quantify barrier properties have to achieve a good correlation with the permeability measurements of small, polar substances that are not substrates of BBB transporters. For impedance measurements, a constantly low sucrose permeability (value of $\mathrm{p}=10^{-7} \mathrm{~cm} / \mathrm{s}$ ), which is characteristic for the BBB in vivo, was found in cells with TEER values $>600-800 \Omega \cdot \mathrm{cm}^{2}$, while cells exhibiting a lower TEER showed a more variable permeability [11]. When performing transport experiments, it is of great importance to have an online control of barrier properties since a disruption of barrier integrity might result in false interpretation of data.

\section{Nanoparticles at the blood-brain barrier7}

For several years, nanoparticles have been proposed as vehicles for drug delivery across the BBB. Recently, we have found that poly(butyl)cyanoacrylate nanoparticles (PBCA-NP) are able to temporarily open the bloodbrain barrier [20]. After addition of PBCA-NP to porcine endothelial cells, a drastic decrease in barrier integrity was observed during $2 \mathrm{~h}$, followed by a recovery of the barrier within the next $3-4 \mathrm{~h}$ (Figure 6). The observed reversible opening of the blood-brain barrier was also confirmed by sucrose and high molecular dextran permeability

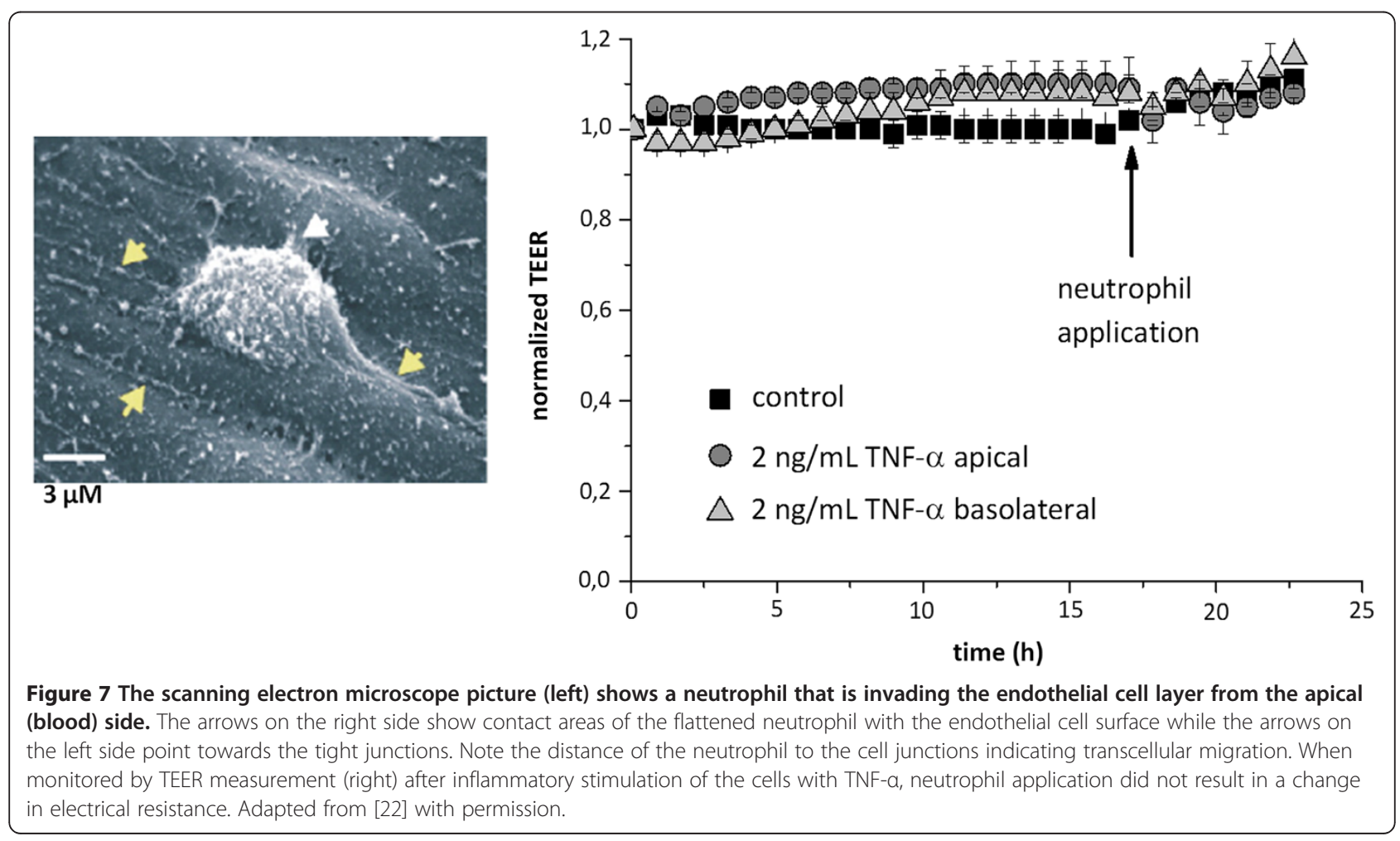


showing that the time-frame of barrier opening could also be employed to transfer a substance of interest from the blood-stream into the brain.

Using impedance measurements, it is also possible to ascertain the toxicity of nanomaterials. Wagner et al. [21] have combined different oximes for treatment of organophosphate poisoning with human serum albumin nanoparticles to enable transport across the BBB. Using impedance spectroscopy, they were able to verify the presence of an intact barrier during their transport studies. Additionally, impedance measurements were used to assess the toxicity of the used nanoparticles underlining the results obtained from cytotoxicity assays.

\section{Inflammatory cells cross the blood-brain barrier without opening the tight junctions}

In several central nervous system diseases that involve $\mathrm{BBB}$ dysfunction an immense infiltration of the brain with leucocytes takes place. In general, two routes for their transmigration are being discussed. The transmigration could either take place via the paracellular route which would require a transient $\mathrm{BBB}$ breakdown, or via the transcellular pathway through the endothelial cell body. The latter route would probably not interfere with the tight junction organization and thereby leave the barrier intact. By an advanced microscopic in vitro study in a high-barrier porcine model, it has been shown that the diapedesis of leukocytes preferentially uses the transcellular route [22,23]. Here, a combination of impedance spectroscopy and advanced ultra-structural investigation demonstrated the lack of barrier impairment during the penetration process (Figure 7).

\section{Pericytes and astrocytes regulate the blood-brain barrier integrity}

In vivo, the $\mathrm{BBB}$ properties are not solely due to the properties of capillary endothelial cells but are also induced by surrounding pericytes and astrocytes. The in vitro induction of $\mathrm{BBB}$ properties by astrocytes was characterized by determining the resistance in a co-culture-model of endothelial cells and astrocytes [24,25]. For all conditions tested, it was found that astrocytes increase BBB integrity. Also, the influence of pericytes on the integrity of the BBB is still under discussion. Employing TEER measurements, it was found that pericytes can either decrease or increase the integrity of the barrier, depending on their state of differentiation [26]. With the aid of resistance measurements, Nakagawa et al. were able to ascertain the best culture conditions for the establishment of a triple co-culture model of endothelial cells with astrocytes and pericytes

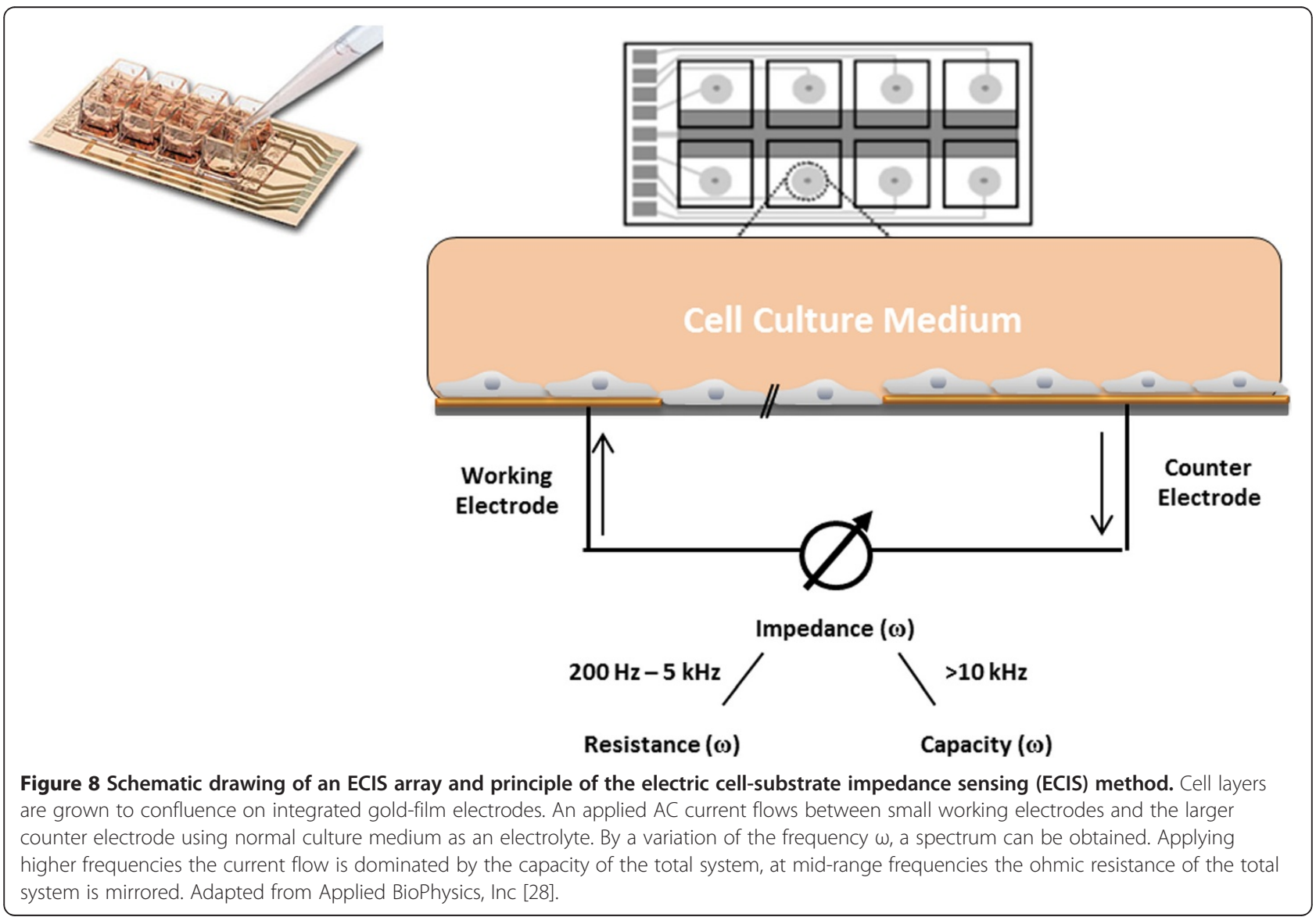




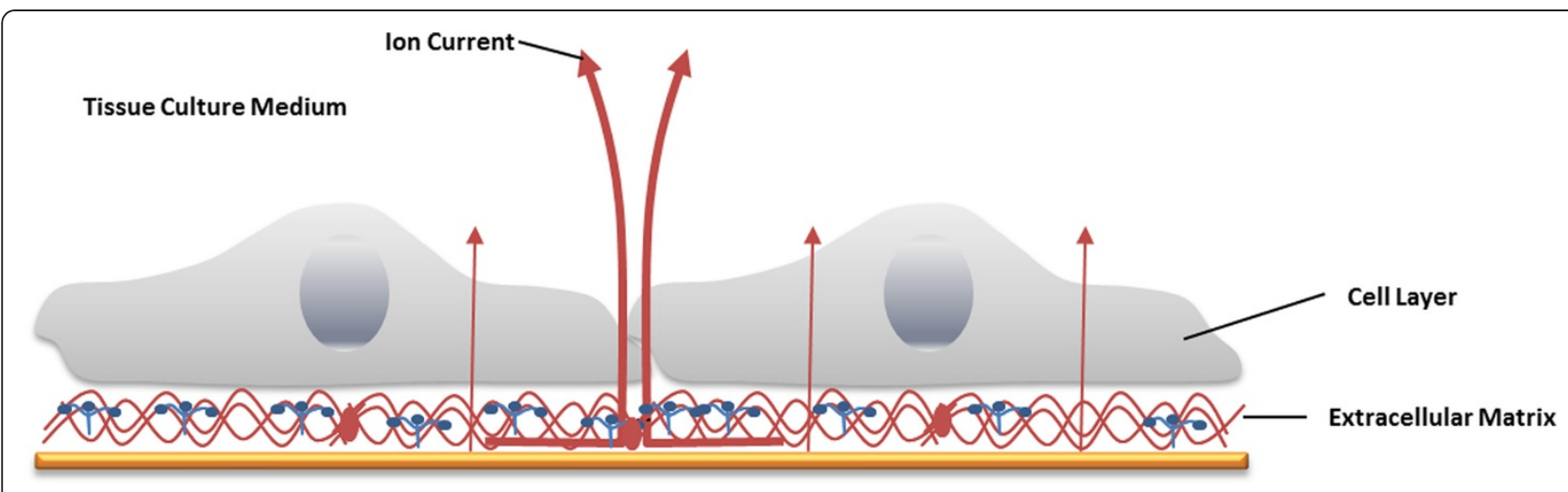

Figure 9 The current pathway at low frequencies on a cerebral endothelial cell monolayer (ECIS method, $400 \mathrm{~Hz}$ ). At low frequencies the current predominantly flows paracellular (through extracellular matrix proteins) and between adjacent cells (through tight junctions) and the electrolyte (medium), see bold arrows. Adapted from Applied BioPhysics, Inc [28].

[27]. The authors were able to show that the presence of astrocytes and pericytes resulted in an increase of TEER compared to the mono-culture.

\section{Electrical cell substrate impedance sensing}

Electric cell-substrate impedance sensing (ECIS, Applied BioPhysics inc, Troy NY, USA) is an impedance-based method, which can be used as a tool for real-time monitoring of the cell behaviour such as adherence, mobility and growth on solid substrates [28]. This technique allows investigation of the invasive nature of cancer cells, the barrier function of endothelial cells, cell-cell and cell-matrix interactions, signal transduction for modern drug discovery and wound-healing processes.

In ECIS, cell layers are grown to confluence not on porous membranes but directly on integrated gold-film electrodes. The close proximity of the cell monolayer to the thin gold electrodes results in high sensitivity measurements. However, it is important to realize that there is no basolateral fluid compartment present due to the adherence of the cells to the electrode. This excludes the employment of the ECIS setup in transport or transfer experiments. There are also fundamental differences in the measured impedance data that need to be considered when comparing results obtained with membranebased experimental setups such as the cellZscope [29]. This will be enlightened by some basic calculations in the following paragraph.

The ECIS array is typically composed of 8 wells which each contain 10 active working electrodes (diameter $=$ $250 \mu \mathrm{m})$ connected in parallel (total area $=5 \times 10^{-3} \mathrm{~cm}^{2}$, single electrode area $=5 \times 10^{-4} \mathrm{~cm}^{2}$ ) and a larger in-plane counter electrode (area $=0.15 \mathrm{~cm}^{2}$ ), which are located at the base of the well. The core component of the arrays is the single impedance measurement chamber sketched in Figure 8. Because of the size differences in the electrodes, the measured electrical resistance is mainly determined by the working electrode. Due to the much smaller surface area of the active ECIS working electrodes $\left(5 \times 10^{-3} \mathrm{~cm}^{2}\right)$ compared to a typical membrane insert and the corresponding electrode of about the same size (in the range of 0.3 to $4.7 \mathrm{~cm}^{2}$ ), the measured absolute impedance values differ significantly. If the ECIS device measures an absolute resistance of $1000 \Omega$ at a given frequency, the results

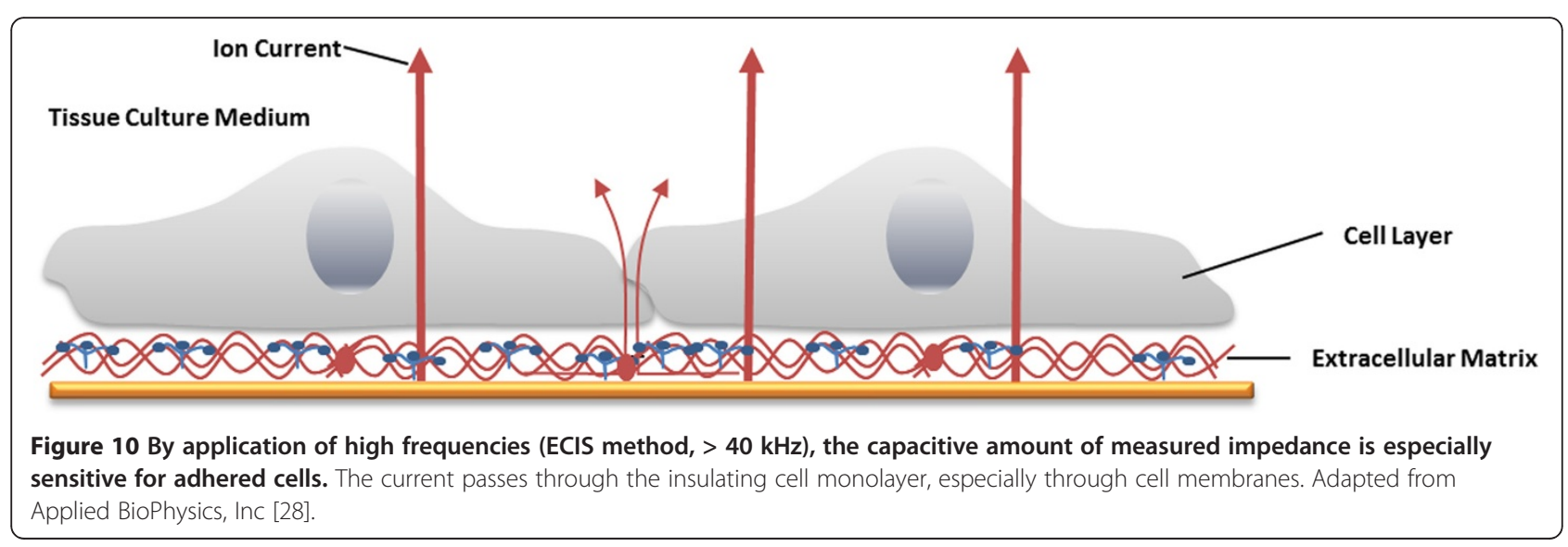



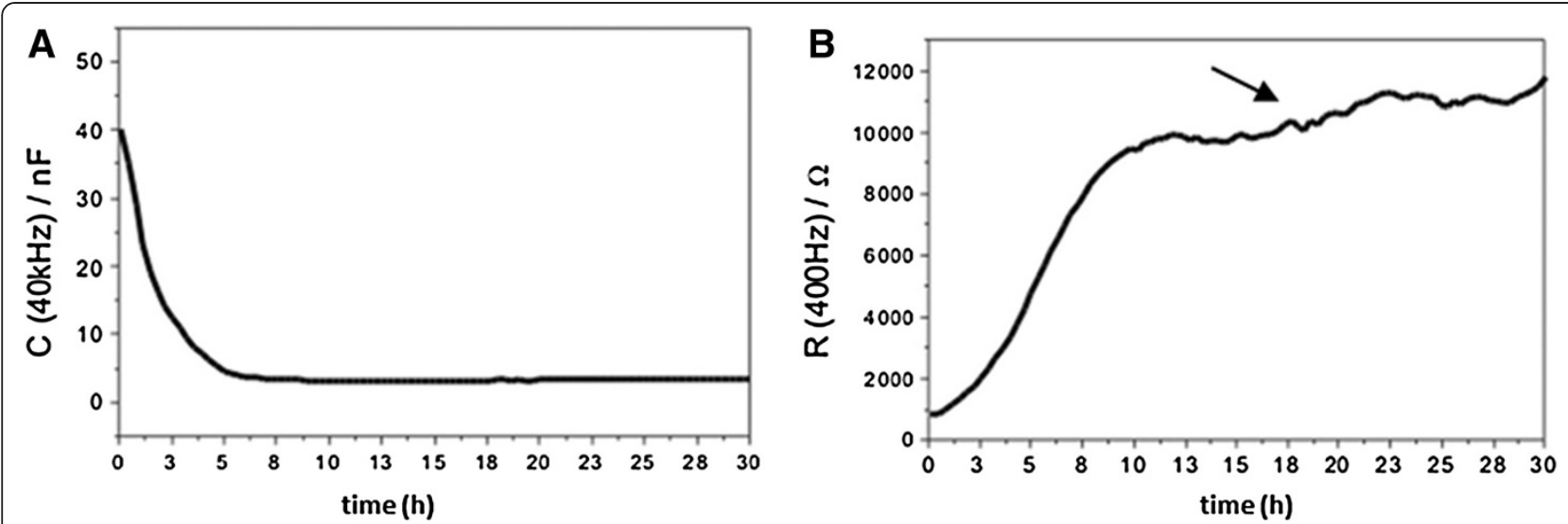

Figure 11 Determination of the adhesion process and progression of the resistance of cells on ECIS arrays with time. (A) The adhesion process can be determined by application of the frequency $(f>40 \mathrm{kHz})$. (B) By application of a frequency $(\mathrm{f}<400 \mathrm{~Hz})$ the development of cellcell contacts (tight junctions) can be monitored. Bold arrow indicates the small fluctuations on the electrode due to micro motion in the cell monolayers. From [31] with permission.

should be normalized by multiplying with the surface area of the working electrodes amounting to $5 \Omega \cdot \mathrm{cm}^{2}$. This is a very low value typical for very leaky epithelia or endothelia, even though the measured value of $1000 \Omega$ seems to be large at first glance. However, tight barriers should be expected to exhibit TEER values of $1000 \Omega \cdot \mathrm{cm}^{2}$ or more, which corresponds to absolute resistance values of $200,000 \Omega$ or more in an ECIS system. In case of the cellZscope the membrane area of the specific insert type is considered by the software and the TEER is automatically normalized and always given in $\Omega \cdot \mathrm{cm}^{2}$. This kind of normalisation to the active surface area is mandatory for comparing results obtained with different techniques.

An additional application of ECIS is to determine the electrical resistance of the cell-covered electrodes, as a function of AC frequency. At low frequencies, as cells attach and spread on the electrode surface, they act like insulting particles, forcing the current to flow around the cellular bodies on paracellular pathways. Thus, the ohmic resistance of the total system depends on the application of lower frequencies [30] (Figure 9). At high frequencies $(f>10 \mathrm{kHz})$ the majority of the current passes capacitatively across the basal and the apical cell membranes (transcellular pathway, Figure 10). Wegener et al. have proved that resistance measured at an $\mathrm{AC}$ frequency, $\mathrm{f}$, of $<400 \mathrm{~Hz}$ is most sensitive for monitoring the establishment of cell-cell junctions as a function of time. Real-time monitoring and quantitative data for the adhesion process of cells on the electrodes can be measured at $\mathrm{f}>40 \mathrm{kHz}$, which is a sensitive frequency range. Corresponding values for tight epithelia would be $\mathrm{f}<$ $10 \mathrm{~Hz}$ and $\mathrm{f} \sim 1000 \mathrm{~Hz}$. Thereby, the progress of developing cell-cell contacts can be monitored during and after absorption of cells to the surface [30].

\section{Cell attachment and cell growth}

ECIS allows researchers to monitor the attachment and spreading of mammalian cells in temporal resolution. Wegener et al. demonstrated that high frequency capacitance measurements $(\mathrm{f}=40 \mathrm{kHz})$ are most suited to follow the increasing surface coverage of the electrodes by cells (Figure 11A, [31]). The impedance increases during the adherence to and spreading of cells over the

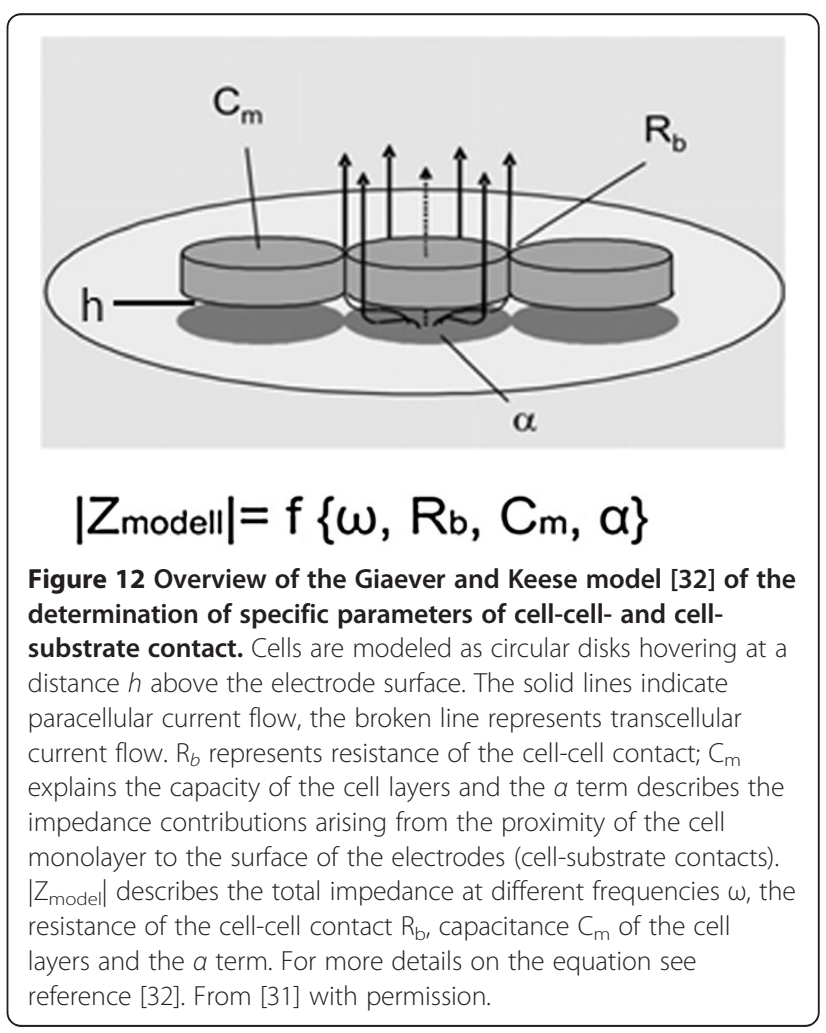



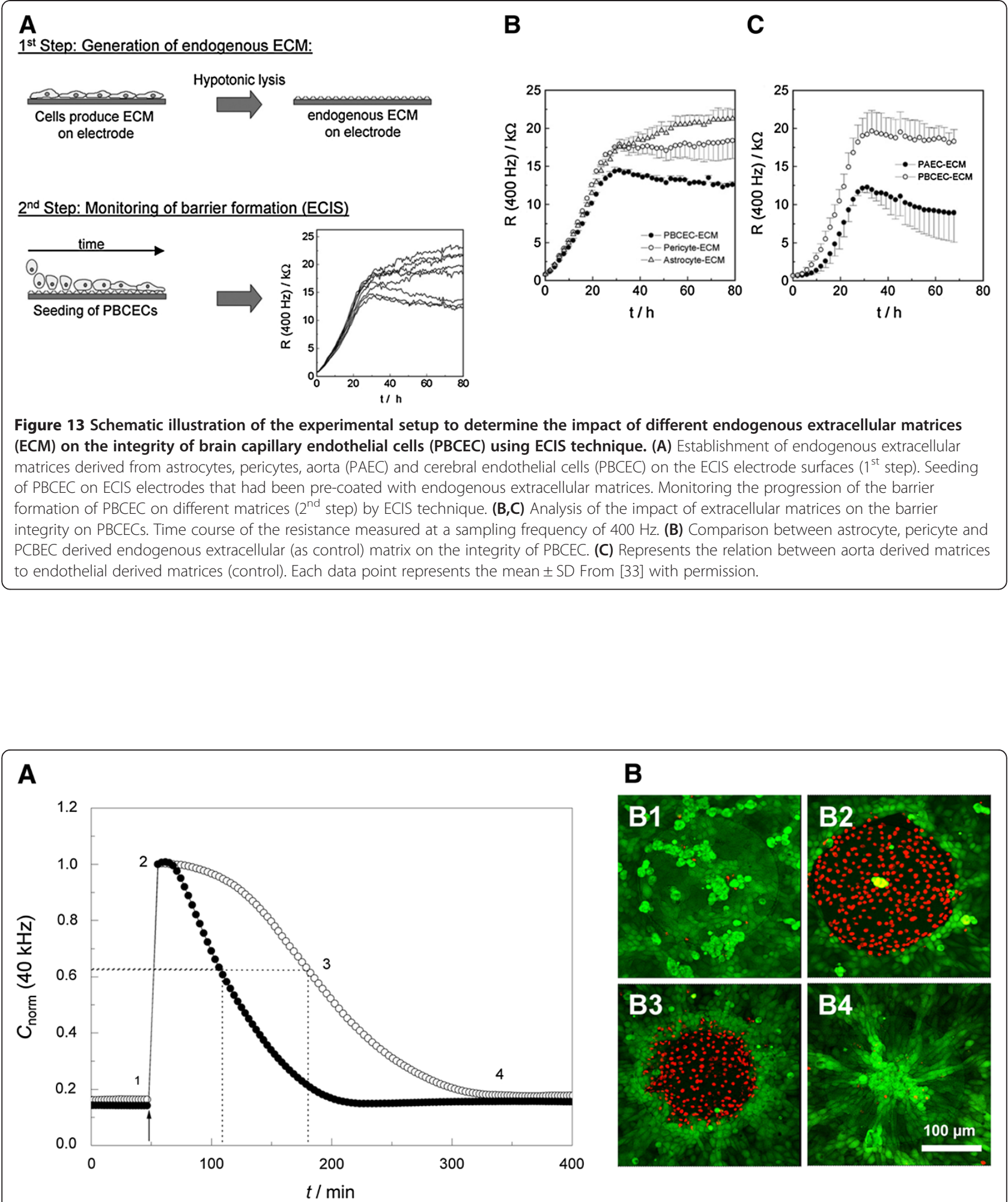

B
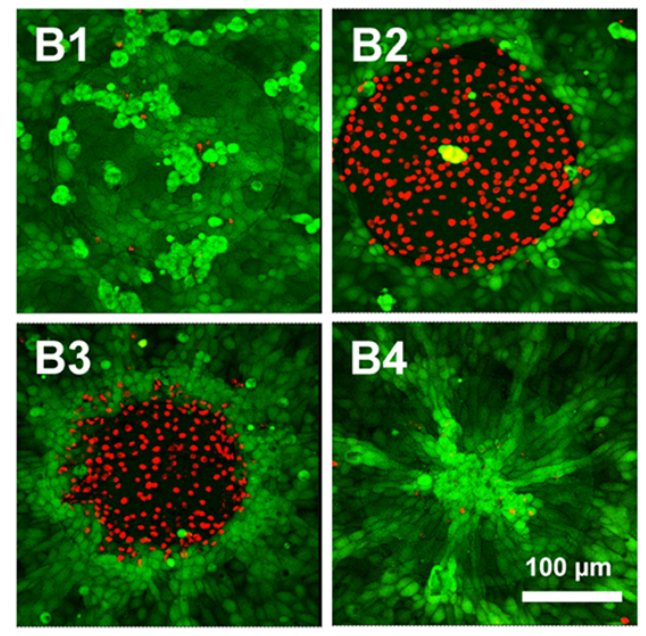

Figure 14 (A) Time course of normalized capacitance $\mathrm{C}$ of a sampling frequency of $\mathbf{4 0} \mathrm{kHz}$ wounding of normal rat kidney (NRK) epithelial cells (wounding parameters: $\mathbf{4} \mathrm{V}, \mathbf{2 0 ~ s ,} \mathbf{4 0} \mathbf{~ k H z}$ ). The arrow indicates the time point of injury (2). (B) Confocal laser scanning microscopy (CLSM) images of the Live/Dead Assay show vital cells surrounding the active electrode surface (calcein acetoxymethylester stained in green) and dead cells (ethidium homodimer-1 stained in red) on the electrode itself. (B; 1-4) Documentation of the wound healing process by CLSM images, 1 = before wounding, 2 = after wounding, $3=$ after partial wound healing, $4=$ after complete wound healing. From [34] with permission. 
electrode and and continues to increase within 10 hours, when porcine brain capillary endothelial cells (PBCEC) reach confluence (Figure 11B, [31]). The high sensitivity of the ECIS technique and its simultaneous high temporal resolution of one second, allows recording and analysis of the smallest cell movements and cell shape fluctuations in confluent monolayers, called micro motion [32]. The small fluctuations in the curves (Figure 11B, bold arrow) are due to micro motion of the cell monolayers on the electrode.

Besides the determination of the capacitance and impedance by using different frequencies, the analysis of the cell-cell contacts $\left(R_{b}\right)$, the capacitance of the cell layers $\left(\mathrm{C}_{\mathrm{m}}\right)$, and the close proximity of the cell monolayer to the surface of the electrodes, allows direct analysis of the amount of the impedance of the cell-matrix contacts $(\alpha)$. The cells are represented as cylinders, which keep a middle distance (h) to the surface of the gold electrodes (Figure 12) [32]. The cell-cell $R_{b}$ and cell-substrate contacts, $\alpha$, are serially connected and reflect the paracellular current flow. In parallel the transcellular current flows in a capacitive way through the cell membrane $\left(C_{m}\right)$.

\section{Extracellular matrix coating of ECIS electrodes}

To clarify the impact of endogenous extracellular matrices on the barrier integrity of PBCEC, a generation model was established in two consecutive steps. The extracellular matrix (ECM)-donating cells (astrocytes, pericytes or endothelial cells) were grown to confluence and removed by a hypotonic lysis procedure from their ECMs (Figure 13A). Suspensions of PBCEC were seeded on the remaining matrices and the formation of the $\mathrm{BBB}$ was monitored at a frequency of $\mathrm{R}(400 \mathrm{~Hz} / \mathrm{k} \Omega)$ over a defined period of time (Figure 13B; C). The authors observed an improved integrity of the $\mathrm{BBB}$ by pericyte- and astrocyte-derived ECM compared to endothelial cell-derived ECM alone, which served as a control (B). Non-brain capillary aorta endothelial cell-derived ECM markedly reduced the electrical resistance of PBCEC (C) [33].

\section{Wound healing}

In a wound healing-assay, cell monolayers on ECIS electrodes were subjected to an insulting current, resulting in severe electroporation and subsequent cell death. The authors were able to monitor the ultimate healing after electrical wounding of normal rat kidney (NRK) epithelial cells over a period of time (Figure 14A) and to determine the time points of the ingrowth of cells from the periphery to the electrodes by using confocal laser scanning microscopy (CLSM) (Figure 14B) [34]. Besides finding a suitable frequency for wounding, the amplitude and the pulse duration of the wounding pulse had to be optimized as well. Wounding parameters for NRK cells were $4 \mathrm{~V}, 20 \mathrm{~s}, 40 \mathrm{kHz}$.

\section{Two-path impedance spectroscopy}

So far we have only considered changes in the paracellular resistance and the sub-epithelial resistance caused by the cell attachment. However, solutes may also be transported via a transcellular way crossing the apical and the basolateral membrane. Thus, it might become desirable to determine the para- and the transcellular resistance separately. This is especially important if ion fluxes via ion channels are involved. Krug et al. have developed a technique based on impedance spectroscopy which enables them to differentiate between the transcellular and paracellular pathways. In combination with flux measurements using e.g. fluorescein as a paracellular marker they are able to determine the transcellular resistance as well [35].

\section{Conclusions}

Electrical resistance measurements are valuable tools to quantify barrier properties. Impedance spectroscopy is a new non-invasive technique to monitor not only barrier function but also processes, like cell growth and cell differentiation. The main advantage of impedance spectroscopy is the automated monitoring process. Two main systems have to be distinguished. One is the cellZscope device, using standard cell culture inserts with semipermeable membranes as substrates for cell growth, thus allowing simultaneous transport investigations. The second is the ECIS system, where the cells are directly grown on the electrode thus losing their basolateral compartment. However, in addition the value $\alpha$ which characterises the cell-matrix interaction, can be determined. Moreover, since higher currents might be applied locally, cells can be locally destroyed to allow measurements of wound healing. Thus, both experimental methods are important, their use depending on the scientific question under investigation.

\section{Abbreviations \\ a: Impedence Of Cell-Matrix Contacts; AC: Alternating Current; BBB: Blood- brain Barrier; $C_{C l}$ : Capacitance Of The Cell Membrane; $C_{\mathrm{El}}$ : Capacitance Of The Electrodes; $C_{m}$ : Capacitance Of The Membrane In ECIS; CLSM: Confocal Laser Scanning Microscopy; CSF: Cerebrospinal Fluid; DC: Direct Current; ECIS: Electrical Cell Substrate Impedance Sensing; ECM: Extracellular Matrix; EVOM: Epithelial Voltohmmeter; F: Frequency; I: Current; NRK: Normal Rat Kidney; PBCA-NP: Poly(Butyl)Cyanoacrylate - Nanoparticles; PBCEC: Porcine Brain Capillary Endothelial Cells; R: Ohmic Resistance; $R_{b}$ : Ohmic Resistance Of Cell-Cell Contacts; $R_{\text {membrane: Ohmic Resistance Of The Membrane; }}$ TEER: Transendothelial Electrical Resistance; TNF-a: Tumor Necrosis Factor - a; U: Voltage; Z: Impedance.}

\section{Competing interests}

Prof. Galla is a scientific advisor of the nanoAnalytics $\mathrm{GmbH}$, manufacturer of cellZscope $^{\circledR}$

\section{Authors' contributions}

All authors contributed equally. All authors have read and approved the final version of the manuscript.

\section{Acknowledgements}

We like to thank Dr. Boris Anzcykowski from Nanoanalytics GmbH for helpful discussions and continuous support. The input of Prof Dr. Joachim Wegener, 
Institute for Analytical chemistry, Chemo- and Biosensors at the University of Regensburg in the development of the impedance spectroscopy is especially acknowledged.

Received: 1 October 2012 Accepted: 19 December 2012

Published: 10 January 2013

\section{References}

1. Abbott NJ, Ronnback L, Hansson E: Astrocyte-endothelial interactions at the blood-brain barrier. Nat Rev Neurosci 2006, 7:41-53.

2. Cho C-W, Liu Y, Cobb W, Henthorn T, Lillehei K, Christians U, Ng K-Y: Ultrasound-induced mild hyperthermia as a novel approach to increase drug uptake in brain microvessel endothelial cells. Pharm Res 2002, 19:1123-1129.

3. Rapoport SI: Osmotic opening of the blood-brain barrier: principles, mechanism, and therapeutic applications. Cell Mol Neurobiol 2000, 20:217-230.

4. Schirmacher A, Winters S, Fischer S, Goeke J, Galla HJ, Kullnick U, Ringelstein $E B$, Stogbauer F: Electromagnetic fields $(1.8 \mathrm{GHz})$ increase the permeability to sucrose of the blood-brain barrier in vitro. Bioelectromagnetics 2000, 21:338-345.

5. Deli MA, Abraham CS, Kataoka Y, Niwa M: Permeability studies on in vitro blood-brain barrier models: physiology, pathology, and pharmacology. Cell Mol Neurobiol 2005, 25:59-127.

6. Bowman PD, Ennis SR, Rarey KE, Betz AL, Goldstein GW: Brain microvessel endothelial cells in tissue culture: a model for study of blood-brain barrier permeability. Ann Neurol 1983, 14:396-402.

7. Franke H, Galla H-J, Beuckmann CT: An improved low-permeability in vitro-model of the blood-brain barrier: transport studies on retinoids, sucrose, haloperidol, caffeine and mannitol. Brain Res 1999, 818:65-71.

8. Roux F, Durieu-Trautmann O, Chaverot N, Claire M, Mailly P, Bourre JM, Strosberg AD, Couraud PO: Regulation of gamma-glutamyl transpeptidase and alkaline phosphatase activities in immortalized rat brain microvessel endothelial cells. J Cell Physiol 1994, 159:101-113.

9. Muruganandam A, Herx LM, Monette R, Durkin JP, Stanimirovic DB: Development of immortalized human cerebromicrovascular endothelia cell line as an in vitro model of the human blood-brain barrier. FASEB $J$ 1997, 11:1187-1197.

10. Gumbleton M, Audus KL: Progress and limitations in the use of in vitro cell cultures to serve as a permeability screen for the blood-brain barrier. J Pharm Sci 2001, 90:1681-1698.

11. Lohmann C, Hüwel S, Galla H-J: Predicting blood-brain barrier permeability of drugs: evaluation of different In vitro assays. J Drug Target 2002, 10:263-276.

12. Epithelial voltohmmeter for TEER. http://www.wpiinc.com/index.php/vmchk EVOM2.html.

13. Jovov B, Wills NK, Lewis SA: A spectroscopic method for assessing confluence of epithelial cell cultures. Am J Physiol 1991, 261:C1196-C1203.

14. Homepage NanoAnalytics. http://www.nanoanalytics.de/de.

15. Galla H-J, Thanabalasundaram G, Wedel-Parlow M, Rempe RG, Kramer S, El-Gindi J, Schäfer M, Anczykowski B: The blood-brain-barrier in vitro: regulation, maintenance and quantification of the barrier properties by impedance spectroscopy. In Horizons in neuroscience research. Edited by Costa A, Villalba E. New York: Nova; 2011:1-14.

16. Macdonald JR, Johnson WB: Fundamentals of impedance spectroscopy. In Impedance spectroscopy. Edited by Macdonald JR. New York: WileyInterscience; 1987:1-20.

17. Hoheisel D, Nitz T, Franke H, Wegener J, Hakvoort A, Tilling T, Galla H-J: Hydrocortisone reinforces the blood-brain barrier properties in a serum free cell culture system. Biochem Biophys Res Com 1998, 244:312-316.

18. Wegener J, Abrams D, Willenbrink W, Galla HJ, Janshoff A: Automated multi-well device to measure transepithelial electrical resistances under physiological conditions. Biotechniques 2004, 37:590, 592-594-596-597.

19. Weidenfeller C, Schrot S, Zozulya A, Galla H-J: Murine brain capillary endothelial cells exhibit improved barrier properties under the influence of hydrocortisone. Brain Res 2005, 1053:162-174.

20. Rempe R, Cramer S, Hüwel S, Galla H-J: Transport of poly(n-butylcyanoacrylate) nanoparticles across the blood-brain barrier in vitro and their influence on barrier integrity. Biochem Biophys Res Com 2011, 406:64-69.
21. Wagner S, Kufleitner J, Zensi A, Dadparvar M, Wien S, Bungert J, Vogel T, Worek F, Kreuter J, von Briesen H: Nanoparticulate transport of oximes over an In vitro blood-brain barrier model. PLoS One 2010, 5:e14213.

22. von Wedel-Parlow M, Schrot S, Lemmen J, Treeratanapiboon L, Wegener J, Galla H-J: Neutrophils cross the BBB primarily on transcellular pathways: an in vitro study. Brain Res 2011, 1367:62-76.

23. von Wedel-Parlow M, Galla H-J: A microscopic in vitro study of neutrophil diapedesis across the blood-brain barrier. In Microscopy: science, technology, applications and education 2. Edited by Méndez-Vilas A, Díaz J. Badajoz, Spain: Formatex; 2010:1161-1167.

24. Kröll S, El-Gindi J, Thanabalasundaram G, Panpumthong P, Schrot S, Hartmann C, Galla H-J: Control of the blood-brain barrier by glucocorticoids and the cells of the neurovascular unit. Ann N Y Acad SCi 2009, 1165:228-239.

25. Dehouck M-P, Méresse S, Delorme P, Fruchart J-C, Cecchelli R: An easier, reproducible, and mass-production method to study the blood-brain barrier In vitro. J Neurochem 1990, 54:1798-1801.

26. Thanabalasundaram G, Schneidewind J, Pieper C, Galla H-J: The impact of pericytes on the blood-brain barrier integrity depends critically on the pericyte differentiation stage. Int J Biochem Cell Biol 2011, 43:1284-1293.

27. Nakagawa S, Deli MA, Kawaguchi H, Shimizudani T, Shimono T, Kittel A, Tanaka K, Niwa M: A new blood-brain barrier model using primary rat brain endothelial cells, pericytes and astrocytes. Neurochem Int 2009, 54:253-263.

28. Applied Bio Physics. http://www.biophysics.com/ecis-theory.php.

29. Wegener J, Hakvoort A, Galla H-J: Barrier function of porcine choroid plexus epithelial cells is modulated by cAMP-dependent pathways in vitro. Brain Res 2000, 853:115-124.

30. Wegener J, Keese CR, Giaever I: Electric cell-substrate impedance sensing (ECIS) as a noninvasive means to monitor the kinetics of cell spreading to artificial surfaces. Exp Cell Res 2000, 259:158-166.

31. Hartmann C: Der induktive und protektive Einfluss der extrazellulären Matrix auf die Blut-Hirn Schranke in vitro. In PhD thesis. Münster: Westfälische-Wilhelms Universität; 2007.

32. Giaever I, Keese CR: Micromotion of mammalian cells measured electrically. Proc Natl Acad Sci U S A 1991, 88:7896-7900.

33. Hartmann C, Zozulya A, Wegener J, Galla H-J: The impact of glia-derived extracellular matrices on the barrier function of cerebral endothelial cells: an in vitro study. Exp Cell Res 2007, 313:1318-1325.

34. Michaelis S, Robelek R, Wegener J: Studying cell-surface interactions In vitro: a survey of experimental approaches and techniques. In Tissue engineering III: cell - surface interactions for tissue culture. Edited by Kasper C, Witte F, Pörtner R. Berlin: Springer Verlag Berlin Heidelberg; 2012:33-66.

35. Krug SM, Fromm M, Gunzel D: Two-path impedance spectroscopy for measuring paracellular and transcellular epithelial resistance. Biophys J 2009, 97:2202-2211.

doi:10.1186/2045-8118-10-5

Cite this article as: Benson et al.: Impedance-based cell monitoring: barrier properties and beyond. Fluids and Barriers of the CNS 2013 10:5.

\section{Submit your next manuscript to BioMed Central and take full advantage of:}

- Convenient online submission

- Thorough peer review

- No space constraints or color figure charges

- Immediate publication on acceptance

- Inclusion in PubMed, CAS, Scopus and Google Scholar

- Research which is freely available for redistribution 